\title{
The difluoromethylenephosphonothioic acid group as a phosphate surrogate for obtaining PTP-1B inhibitors. Transformation of difluoromethylenephosphonic acids into difluoromethylenephosphonothioic acids
}

\author{
Tetsuo Murano, ${ }^{a}$ Hiroaki Takechi, ${ }^{a}$ Yoko Yuasa, ${ }^{a}$ Tsutomu Yokomatsu, ${ }^{\text {a,* }}$ Ikuko Umesue, \\ Shinji Soeda, ${ }^{b}$ Hiroshi Shimeno, ${ }^{b}$ and Shiroshi Shibuya ${ }^{a}$ \\ ${ }^{a}$ School of Pharmacy, Tokyo University of Pharmacy \& Life Science \\ 1432-1 Horinouchi, Hachioji, Tokyo 192-0392, Japan, ${ }^{b}$ Faculty of Pharmaceutical Sciences, \\ Fukuoka University, 8-9-1 Nanakuma, Jonan-ku, Fukuoka 841-0180, Japan \\ E-mail: yokomatu@ps.toyaku.ac.jp
}

Dedicated to Professor Keiichiro Fukumoto on his $70^{\text {th }}$ birthday

(received 22 July 03; accepted 12 Oct 03; published on the web 30 Oct 03)

\begin{abstract}
Aryldifluoromethylphosphonic acids were transformed into the corresponding phosphonothioic acids via their bis-(2-cyanoethyl) esters for the evaluation of their biological effects on protein tyrosine phosphatase 1B. Difluoro(2-naphthyl)-methylphosphonothioic acid 5d showed better inhibitory potency and higher hydrophobicity than the corresponding difluoromethylenephosphonic acid analogue 1d.
\end{abstract}

Keywords: Phosphonothioic acids, bis-(2-cyanoethyl) esters, enzyme inhibitors, protein tyrosine phosphatases

\section{Introduction}

Naturally-occurring phosphate derivatives play pivotal roles in various cellular processes including signal transduction. ${ }^{1}$ Non-hydrolyzable phosphate mimetics have been studied for the design of potential enzyme inhibitors and probes for the elucidation of biochemical processes. Extensive studies have been devoted to the synthesis and biological evaluation of $(\alpha, \alpha-$ difluoromethylene)phosphonic acid (DFMPA) derivatives 1, as non-hydrolyzable mimetics of phosphates. ${ }^{2}$ As a result, many enzyme inhibitors with significant activity have been identified. ${ }^{3}$ Although the DFMPA group has proved to be useful for obtaining inhibitors against a variety of enzymes, highly polar and hydrophilic DFMPA-derivatives often exhibit poor cellular uptake. ${ }^{4}$ Consequently, recent efforts in this research field are focused on developing new-generation 
mimetics of a phosphate ester. ${ }^{5}$ Among them, ( $\alpha, \alpha$-difluoromethylene)phosphonothioic acid (DFMPTA) derivatives, 2, featuring a less-polar phosphorus-sulfur bond, ${ }^{6}$ are proposed as a class of non-hydrolyzable phosphate mimetics possessing unique and useful properties. ${ }^{7}$ However, the physical and biological properties of DFMPTA compounds have not been studied extensively, owing to the lack of efficient synthetic methods.<smiles>[R]C(F)(F)P(=O)(O)O</smiles>

1 (DFMPA)<smiles>[R]C(F)(F)P(O)(O)=S</smiles>

2 (DFMPTA)

\section{Figure 1}

In the search for DFMPA-based inhibitors of protein tyrosine phosphatases (PTPs), which are key regulatory enzymes in many cellular processes such as cell proliferation and differentiation, we and others have identified the novel DFMPA derivatives $\mathbf{1 b}, \mathbf{1 d}$ and $\mathbf{1 e}$, which acted as small molecular inhibitors for protein tyrosine phosphatase $1 \mathrm{~B}$ (PTP-1B). ${ }^{4,5}$ As a part of our program to create small molecular inhibitors of PTP-1B with a better inhibition profile, we became interested in the synthesis and biological evaluation of their DFMPTA analogues. In this paper, we describe an efficient method for the transformation of DFMPAs into DFMPTAs. We also report the results of preliminary studies on the inhibitory activity of the DFMPTA analogues against PTP-1B.
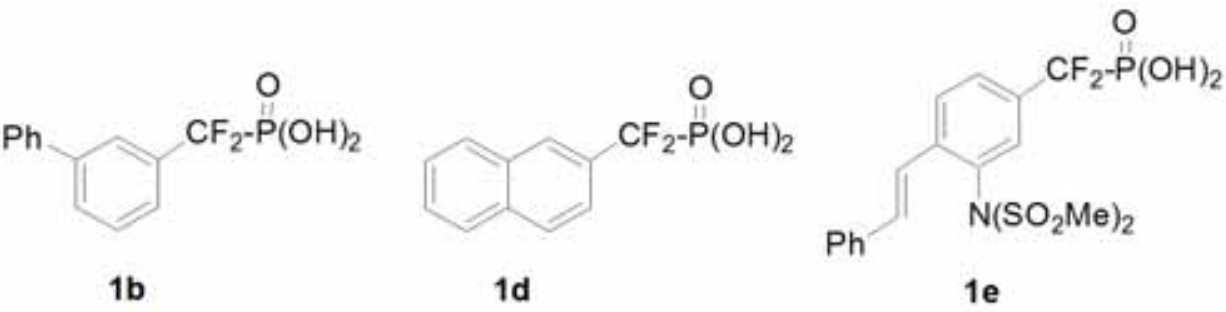

Figure 2

\section{Results and Discussion}

\section{Synthesis of aryldifluoromethylphosphonothioic acids}

Although $O, O$-diethyl aryldifluoromethylphosphonothioates 3 could be synthesized readily, ${ }^{9}$ the deprotection of $\mathbf{3}$ to the free acids 5 using trimethylsilyl bromide (TMSBr), a conventional deprotecting reagent for diethyl phosphonates, was problematic. ${ }^{7,9,10}$ Then, we recently devised a new method for converting $\mathbf{3}$ to $\mathbf{5}$ through a sodium iodide-assisted thiono-thiolo rearrangement 
and the subsequent Pd-catalyzed de-allylation reaction, as shown in Scheme $1 .{ }^{9}$ However, it was rather difficult to obtain reproducible yields in the de-allylation step in this sequence.

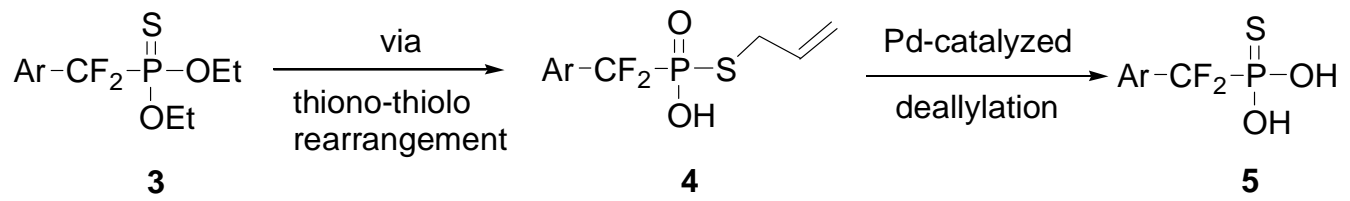

\section{Scheme 1}

Therefore, in the present studies, we examined an alternative method for the synthesis of 5, in which diethyl phosphonates 6a-e were first transesterified with 2-cyanoethanol, ${ }^{11}$ followed by sequential thionylation and deprotection of the 2-cyanoethyl group as shown in Scheme 2. The starting diethyl phosphonates 6a-e were prepared according to the method described previously, and transformed into the corresponding free acids 1a-e by TMSBr-mediated deprotection. ${ }^{8,9,12}$ Treatment of 1a-e with oxalyl chloride in boiling $\mathrm{CH}_{2} \mathrm{Cl}_{2}$ in the presence of $N, N$ dimethylaminopyridine (DMAP) and DMF for $10 \mathrm{~h}$ gave the corresponding dichlorides, which were subsequently treated with 2-cyanoethanol in pyridine to give the bis-(2-cyanoethyl) esters 7a-e in 72-91\% yield. Thionylation of 7a-e with Lawesson's reagent [2,4-bis-(4methoxyphenyl)-1,3-dithia-2,4-diphosphetane-2,4-disulfide] in toluene at $100{ }^{\circ} \mathrm{C}$ gave 8a-e in $47-91 \%$ yield. Deprotection of the 2-cyanoethyl group was achieved with $\mathrm{K}_{2} \mathrm{CO}_{3}$ in $\mathrm{MeOH}$ to give the potassium salts $9 a-\mathbf{a}$ in $47-76 \%$ yield. Acidification of 9d with $1 \mathrm{M} \mathrm{HCl}$, followed by extraction with ether, gave the free acid $5 \mathbf{d}$ in $83 \%$ yield.
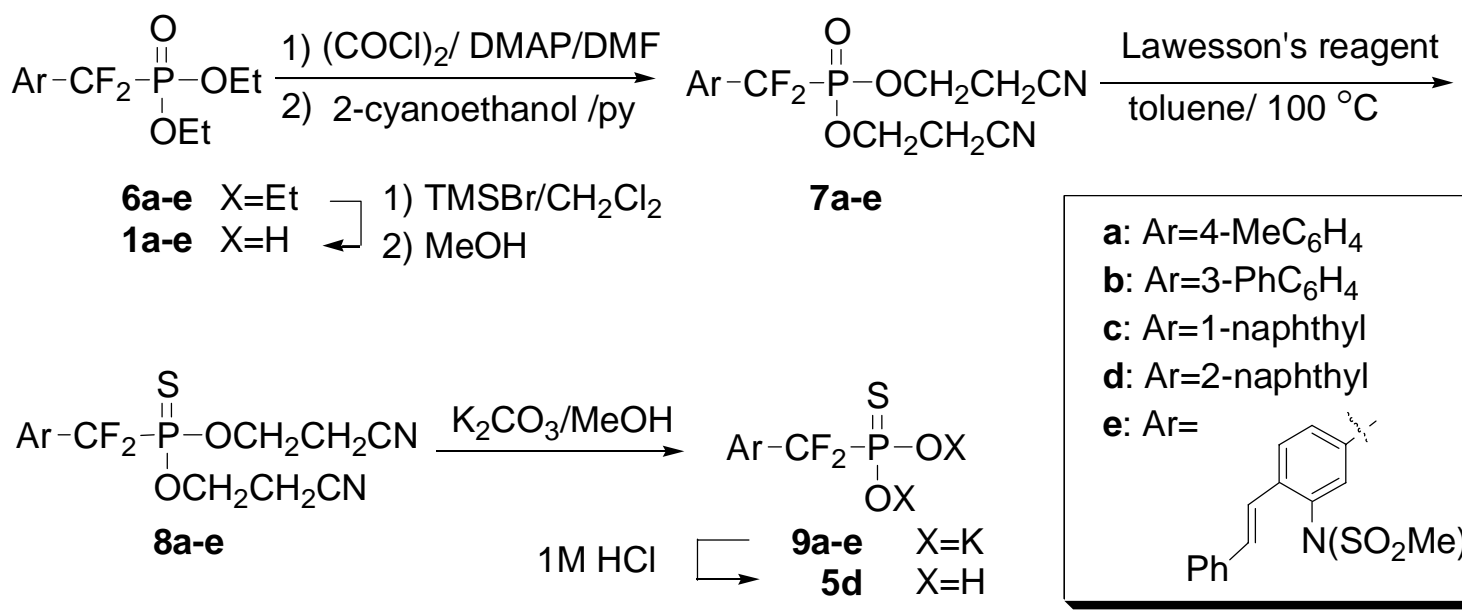

\section{Scheme 2}

\section{Physical properties and biological effects}

To examine the features of DFMPTAs in their physical properties and biological effects, we first determined the octanol/water distribution coefficient $(D)$ of $5 \mathbf{d}$ by a shake-flask method. ${ }^{13}$ The $D$ 
value of the phosphonothioic acid $\mathbf{5 d}$ was estimated to be 0.89 at $25^{\circ} \mathrm{C}$, and is approximately 5 times larger than that $(0.18)$ of the corresponding phosphonic acid analogue 1d. Consequently, 5d is sufficiently lipophilic to be extracted with organic solvents such as ether, whereas 1d could not be extracted with ether from the aqueous solution. The second dissociation constants $\left(\mathrm{pKa}_{2}\right)$ of $5 \mathbf{d}$ and $1 \mathbf{d}$ were also determined to be 4.5 and 5.4, respectively, by a standard titration method. These results reveal that $\mathbf{5 d}$ would exist mainly in the dianionic form at cellular $\mathrm{pH}(6.5)$ as in the case of 1d, but might possess the property of enhancing cellular penetration, owing to its relatively high hydrophobicity. ${ }^{14,15}$

With these observations in mind, we next examined the inhibitory activity of $\mathbf{5 d}$ against PTP$1 \mathrm{~B}$ in comparison with that of $\mathbf{1 d}$. The results are shown in Table 1 . The $\mathrm{IC}_{50}$ of $\mathbf{5 d}$ was determined to be $418.5 \mu M$, which shows that $\mathbf{5 d}$ possesses a slightly higher inhibitory potency than 1d. While the inhibitor $\mathbf{5 d}$ is slightly labile at room temperature, the corresponding potassium salt 9d was found to be stable and shows approximately the same inhibitory potency as 1d. Therefore, the inhibitory potencies for the DFMPTA analogues of $\mathbf{1 b}$ and $\mathbf{1 e}$ were evaluated by using their potassium salts $9 \mathbf{b}$ and 9 e. However, $9 \mathbf{b}$ and $9 \mathbf{e}$ were 5- and 11-times, respectively, poorer inhibitors than their DFMPA analogues $\mathbf{1 b}$ and $\mathbf{1 e}$.

Table 1. $\mathrm{IC}_{50}$ values of aryldifluoromethylphosphonic acids and aryldifluoromethylphosphonothioic acid derivatives against PTP-1B

\begin{tabular}{|c|c|c|c|}
\hline $\mathrm{Ar}-\mathrm{CF}_{2} \mathrm{P}(\mathrm{O})(\mathrm{OH})_{2}$ & $\mathrm{IC}_{50}(\mu \mathrm{M})$ & $\mathrm{Ar}-\mathrm{CF}_{2} \mathrm{P}(\mathrm{S})(\mathrm{OX})_{2}$ & $\begin{array}{c}\mathrm{IC}_{50} \\
(\mu \mathrm{M})\end{array}$ \\
\hline \multirow[t]{2}{*}{ 1d (Ar=2-naphthyl) } & $718.1^{\text {a), b) }}$ & 5d (Ar=2-naphthyl, $\mathrm{X}=\mathrm{H})$ & 418.5 \\
\hline & & 9d (Ar=2-naphthyl, $\mathrm{X}=\mathrm{K})$ & 858.1 \\
\hline $\mathbf{1 b}\left(\mathrm{Ar}=3-\mathrm{PhC}_{6} \mathrm{H}_{4}\right)$ & $252.2^{\mathrm{b})}$ & $9 \mathbf{b}\left(\mathrm{Ar}=3-\mathrm{PhC}_{6} \mathrm{H}_{4}, \mathrm{X}=\mathrm{K}\right)$ & 1204.3 \\
\hline 1e $\left(\mathrm{Ar}=\mathrm{Ph}^{\prime \quad \mathrm{N}\left(\mathrm{SO}_{2} \mathrm{Me}\right)_{2}}\right)$ & $54.1^{\text {a) }}$ & $\left.\left.\mathrm{SO}_{2} \mathrm{Me}\right)_{2}, \mathrm{X}=\mathrm{K}\right)$ & 625.0 \\
\hline
\end{tabular}

a) The value was obtained from ref 8 . ${ }^{\text {b) }}$ The $\mathrm{IC}_{50}$ values of $\mathbf{1 d}$ and $\mathbf{1 b}$ were determined by Taylor to be $35 \mu M$ and $15 \mu M$, respectively, using different assay systems from ours (ref. 5a).

In summary, we have developed an efficient method for the preparation of novel $(\alpha, \alpha-$ difluoromethylene)phosphonothioic acids from ( $\alpha, \alpha$-difluoromethylene)phosphonic acids through thionylation and deprotection of their bis-(2-cyanoethyl) esters. The method allowed us to synthesize DFMPTA-derived aromatic compounds that possess moderate inhibitory potency against PTP-1B.

\section{Experimental Section}


General Procedures. All melting points are uncorrected. All reactions were carried out under a nitrogen atmosphere. NMR data were obtained on a Bruker DPX 400 for a solution in the indicated solvent, unless otherwise specified. ${ }^{13} \mathrm{C}-\mathrm{NMR}(100 \mathrm{MHz})$ and ${ }^{31} \mathrm{P}-\mathrm{NMR}(162 \mathrm{MHz})$ were taken with broadband ${ }^{1} \mathrm{H}$ decoupling. The chemical shifts of ${ }^{31} \mathrm{P}$ are recorded relative to external 85\% $\mathrm{H}_{3} \mathrm{PO}_{4} .{ }^{19} \mathrm{~F}-\mathrm{NMR}$ spectra (376 MHz) were measured using benzotrifluoride (BTF) as an internal reference. PTP-1B was purchased from Upstate Biotech. Inc. "RT" denotes room temperature.

Typical example of preparation of aryldifluoromethylphosphonic acids. Difluoro-(4methyl-phenyl)methylphosphonic acid (1a)

To a stirred solution of $\mathbf{6 a}^{12}(3.14 \mathrm{~g}, 11.3 \mathrm{mmol})$ in $\mathrm{CH}_{2} \mathrm{Cl}_{2}(23 \mathrm{~mL})$ was added $\mathrm{TMSBr}$ (4.47 mL, $33.9 \mathrm{mmol})$. The mixture was stirred at RT for $20 \mathrm{~h}$. The volatile component of the mixture was evaporated and the residue was treated with $\mathrm{MeOH}(23 \mathrm{~mL})$ at $25{ }^{\circ} \mathrm{C}$ for $2 \mathrm{~h}$. The solvent was removed in vacuo to leave a semi-solid. A crystalline material was collected, and washed with cold $\mathrm{CHCl}_{3}$ to give 1a $(2.48 \mathrm{~g}, 98 \%)$. Decomp. 89-90 ${ }^{\circ} \mathrm{C} .{ }^{1} \mathrm{H}$ NMR $\left(\mathrm{CD}_{3} \mathrm{OD}\right) \delta$ $7.47(2 \mathrm{H}, \mathrm{d}, J=8.1 \mathrm{~Hz}), 7.26(2 \mathrm{H}, \mathrm{d}, J=8.1 \mathrm{~Hz}), 2.36(3 \mathrm{H}, \mathrm{s}) .{ }^{13} \mathrm{C}-\mathrm{NMR}\left(\mathrm{CD}_{3} \mathrm{OD}\right) \delta 141.8$, $132.1\left(\mathrm{dt}, J_{\mathrm{CP}}=13.4 \mathrm{~Hz}, J_{\mathrm{CF}}=22.3 \mathrm{~Hz}\right), 129.9,127.2\left(\mathrm{t}, J_{\mathrm{CF}}=6.0 \mathrm{~Hz}\right), 120.0\left(\mathrm{dt}, J_{\mathrm{CP}}=213.8 \mathrm{~Hz}\right.$, $\left.J_{\mathrm{CF}}=260.2 \mathrm{~Hz}\right), 21.3 .{ }^{19} \mathrm{~F}-\mathrm{NMR}\left(\mathrm{CD}_{3} \mathrm{OD}\right) \delta-51.3\left(\mathrm{~d}, J_{\mathrm{PF}}=121.9 \mathrm{~Hz}\right) .{ }^{31} \mathrm{P} \mathrm{NMR}\left(\mathrm{CD}_{3} \mathrm{OD}\right) \delta$ $4.34\left(\mathrm{t}, J_{\mathrm{PF}}=121.9 \mathrm{~Hz}\right)$. IR (KBr) 1602, 1021, 901, $824 \mathrm{~cm}^{-1}$. FAB-MS m/z $223\left(\mathrm{MH}^{+}\right)$. Anal. Calcd for $\mathrm{C}_{8} \mathrm{H}_{9} \mathrm{O}_{3} \mathrm{~F}_{2} \mathrm{P} .2 / 3 \mathrm{H}_{2} \mathrm{O}: \mathrm{C}, 41.04 ; \mathrm{H}, 4.45$. Found: $\mathrm{C}, 40.86 ; \mathrm{H}, 4.46$.

[1,1'-Biphenyl]-3-yl(difluoro)methylphosphonic acid (1b). Prepared from $\mathbf{6 b}^{9}$ in $90 \%$ yield in a manner analogous to that for the preparation of 1a. Decomp. $141{ }^{\circ} \mathrm{C} .{ }^{1} \mathrm{H}$ NMR $\left(\mathrm{CD}_{3} \mathrm{OD}\right) \delta 7.83$ $(1 \mathrm{H}, \mathrm{s}), 7.74(1 \mathrm{H}, \mathrm{d}, J=7.6 \mathrm{~Hz}), 7.63(2 \mathrm{H}, \mathrm{d}, J=7.6 \mathrm{~Hz}), 7.58(1 \mathrm{H}, \mathrm{d}, J=7.6 \mathrm{~Hz}), 7.54(1 \mathrm{H}, \mathrm{d}, J$ $=7.6 \mathrm{~Hz}), 7.45(2 \mathrm{H}, \mathrm{d}, J=7.6 \mathrm{~Hz}), 7.36(1 \mathrm{H}, \mathrm{t}, J=7.6 \mathrm{~Hz}) .{ }^{13} \mathrm{C} \mathrm{NMR}\left(\mathrm{CD}_{3} \mathrm{OD}\right) \delta 142.6,141.5$, $135.6\left(\mathrm{dt}, J_{\mathrm{CP}}=13.4 \mathrm{~Hz}, J_{\mathrm{CF}}=22.1 \mathrm{~Hz}\right), 130.0(2 \mathrm{xC}), 129.9,128.8,128.0,126.1\left(\mathrm{t}, J_{\mathrm{CF}}=6.7\right.$ $\mathrm{Hz}), 125.9\left(\mathrm{t}, J_{\mathrm{CF}}=6.0 \mathrm{~Hz}\right), 119.8\left(\mathrm{dt}, J_{\mathrm{CP}}=212.1 \mathrm{~Hz}, J_{\mathrm{CF}}=260.9 \mathrm{~Hz}\right) .{ }^{19} \mathrm{~F}-\mathrm{NMR}\left(\mathrm{CD}_{3} \mathrm{OD}\right) \delta-$ $46.6\left(\mathrm{~d}, J_{\mathrm{PF}}=113.3 \mathrm{~Hz}\right) .{ }^{31} \mathrm{P}-\mathrm{NMR}\left(\mathrm{CD}_{3} \mathrm{OD}\right) \delta 4.06\left(\mathrm{t}, J_{\mathrm{PF}}=113.3 \mathrm{~Hz}\right) . \mathrm{IR}(\mathrm{KBr}) 3034,1226$, 1048, 928, 755, $701 \mathrm{~cm}^{-1}$. ESI-MS m/z $285\left(\mathrm{MH}^{+}\right)$. Anal. Calcd for $\mathrm{C}_{13} \mathrm{H}_{11} \mathrm{O}_{3} \mathrm{~F}_{2} \mathrm{P}: \mathrm{C}, 54.94 ; \mathrm{H}$, 3.90. Found: C, 54.47; H, 4.06 .

Difluoro(1-naphthyl)methylphosphonic acid (1c). Prepared from $\mathbf{6 c}^{12}(5.43 \mathrm{~g}, 17.3 \mathrm{mmol})$ in $91 \%$ yield in a manner analogous to that for the preparation of 1a. Mp $55-56{ }^{\circ} \mathrm{C}$. ${ }^{1} \mathrm{H}-\mathrm{NMR}$ $\left(\mathrm{CD}_{3} \mathrm{OD}\right) \delta 8.44(1 \mathrm{H}, \mathrm{d}, J=8.0 \mathrm{~Hz}), 7.99(1 \mathrm{H}, \mathrm{d}, J=8.2 \mathrm{~Hz}), 7.94-7.87(1 \mathrm{H}, \mathrm{m}), 7.81(1 \mathrm{H}, \mathrm{d}, J$ $=7.4 \mathrm{~Hz}), 7.57-7.46(3 \mathrm{H}, \mathrm{m}) .{ }^{13} \mathrm{C}-\mathrm{NMR}\left(\mathrm{CD}_{3} \mathrm{OD}\right) \delta 135.6,132.7,131.4,130.8\left(\mathrm{dt}, J_{\mathrm{CP}}=13.1\right.$ $\left.\mathrm{Hz}, J_{\mathrm{CF}}=20.2 \mathrm{~Hz}\right), 129.6,127.7-127.3(2 \mathrm{xC}), 127.0,125.4,121.8\left(\mathrm{dt}, J_{\mathrm{CP}}=211.2 \mathrm{~Hz}, J_{\mathrm{CF}}=\right.$ $261.4 \mathrm{~Hz}) .{ }^{19} \mathrm{~F}-\mathrm{NMR}\left(\mathrm{CD}_{3} \mathrm{OD}\right) \delta-39.6\left(\mathrm{~d}, J_{\mathrm{PF}}=112.3 \mathrm{~Hz}\right) .{ }^{31} \mathrm{P}-\mathrm{NMR}\left(\mathrm{CD}_{3} \mathrm{OD}\right) \delta 4.46\left(\mathrm{t}, J_{\mathrm{PF}}=\right.$ $112.3 \mathrm{~Hz})$. IR (KBr) 1120, 1046, 797, $772 \mathrm{~cm}^{-1}$. FAB-MS m/z $259\left(\mathrm{MH}^{+}\right)$. Anal. Calcd for $\mathrm{C}_{11} \mathrm{H}_{9} \mathrm{O}_{3} \mathrm{~F}_{2} \mathrm{P} . \mathrm{H}_{2} \mathrm{O}: \mathrm{C}, 47.84 ; \mathrm{H}, 4.01$. Found: C, 47.63; H, 4.44.

\{3-[Bis-(methylsulfonyl)amino]-4-[(E)-2-phenylethenyl]phenyl\}(difluoro)methylphosphonic acid (1e). Prepared from $\mathbf{6 e}^{8}(540 \mathrm{mg}, 1 \mathrm{mmol})$ in $96 \%$ yield in a manner analogous to that for the preparation of 1a. Mp $92-94{ }^{\circ} \mathrm{C} .{ }^{1} \mathrm{H} \mathrm{NMR}\left(\mathrm{CD}_{3} \mathrm{OD}\right) \delta 7.99(1 \mathrm{H}, \mathrm{d}, J=8.4 \mathrm{~Hz}), 7.74(1 \mathrm{H}, \mathrm{d}$, 
$J=8.4 \mathrm{~Hz}), 7.62(1 \mathrm{H}, \mathrm{s}), 7.57(2 \mathrm{H}, \mathrm{d}, J=7.4 \mathrm{~Hz}), 7.47(1 \mathrm{H}, \mathrm{d}, J=16.2 \mathrm{~Hz}), 7.38(2 \mathrm{H}, \mathrm{t}, J=7.4$ $\mathrm{Hz}), 7.33(1 \mathrm{H}, \mathrm{d}, J=16.2 \mathrm{~Hz}), 7.30(1 \mathrm{H}, \mathrm{t}, J=7.4 \mathrm{~Hz}), 3.45(6 \mathrm{H}, \mathrm{s}) .{ }^{13} \mathrm{C} \mathrm{NMR}\left(\mathrm{CD}_{3} \mathrm{OD}\right) \delta$ $142.1,137.6,135.4,135.0\left(\mathrm{dt}, J_{\mathrm{CP}}=13.5 \mathrm{~Hz}, J_{\mathrm{CF}}=23.1 \mathrm{~Hz}\right), 133.1,130.9,130.0,129.8,129.4$, $127.9,123.6,119.0\left(\mathrm{dt}, J_{\mathrm{CP}}=211.6 \mathrm{~Hz}, J_{\mathrm{CF}}=261.4 \mathrm{~Hz}\right), 43.4 .{ }^{19} \mathrm{~F} \mathrm{NMR}\left(\mathrm{CD}_{3} \mathrm{OD}\right) \delta-47.1\left(\mathrm{~d}, J_{\mathrm{PF}}\right.$ $=111.0 \mathrm{~Hz}) .{ }^{31} \mathrm{P}-\mathrm{NMR}\left(\mathrm{CD}_{3} \mathrm{OD}\right) \delta 5.43\left(\mathrm{t}, J_{\mathrm{PF}}=111.0 \mathrm{~Hz}\right) . \mathrm{IR}(\mathrm{KBr}) 3040,1369,1159,978$, $764 \mathrm{~cm}^{-1}$. FAB-MS m/z $482\left(\mathrm{MH}^{+}\right)$. Anal. Calcd for $\mathrm{C}_{17} \mathrm{H}_{18} \mathrm{NO}_{7} \mathrm{~F}_{2} \mathrm{PS}_{2} .2 \mathrm{H}_{2} \mathrm{O}: \mathrm{C}, 39.46 ; \mathrm{H}, 4.29$; N, 2.71. Found: C, 39.25; H, 4.42; N, 2.69.

Typical example of preparation of bis-(2-cyanoethyl) phosphonates. bis-(2-Cyanoethyl) difluoro(4-methylphenyl)methylphosphonate (7a)

To a suspension of $1 \mathbf{a}(10 \mathrm{mmol}, 2.22 \mathrm{~g})$ in $\mathrm{CH}_{2} \mathrm{Cl}_{2}(20 \mathrm{~mL})$ containing DMF (78 mg, $\left.1 \mathrm{mmol}\right)$ and DMAP (122 mg, $1 \mathrm{mmol}$ ) was added oxalyl chloride $(3.1 \mathrm{~mL}, 35 \mathrm{mmol})$ over a period of several minutes. The mixture was heated under reflux for $10 \mathrm{~h}$, then concentrated by rotary evaporation to give the crude phosphonic acid dichloride. To a solution of the crude phosphonic acid dichloride in THF (5 mL) was added a solution of 2-cyanoethanol $(1.7 \mathrm{~mL}, 25 \mathrm{mmol})$ and pyridine $(2.0 \mathrm{~mL}, 25 \mathrm{mmol})$ in THF $(5 \mathrm{~mL})$ at $0{ }^{\circ} \mathrm{C}$. After being stirred for $30 \mathrm{~min}$ at $0{ }^{\circ} \mathrm{C}$, then $10 \mathrm{~h}$ at $\mathrm{RT}$, the mixture was poured into saturated aq. $\mathrm{NH}_{4} \mathrm{Cl}$ and extracted with chloroform. The extracts were washed with brine, dried $\left(\mathrm{MgSO}_{4}\right)$ and concentrated. The residue was chromatographed on silica gel (hexane:EtOAc $=1: 1)$ to give 11a $(2.39 \mathrm{~g}, 73 \%)$ as an oil. ${ }^{1} \mathrm{H}$ NMR $\left(\mathrm{CDCl}_{3}\right) \delta 7.52(2 \mathrm{H}, \mathrm{d}, J=7.8 \mathrm{~Hz}), 7.30(2 \mathrm{H}, \mathrm{d}, J=7.8 \mathrm{~Hz}), 4.45-4.33(2 \mathrm{H}, \mathrm{m}), 4.32-4.21(2 \mathrm{H}$, $\mathrm{m}), 2.76-2.63(4 \mathrm{H}, \mathrm{m}), 2.41(3 \mathrm{H}, \mathrm{s}) .{ }^{13} \mathrm{C} \mathrm{NMR}\left(\mathrm{CDCl}_{3}\right) \delta 141.7,129.3,128.0\left(\mathrm{dt}, J_{\mathrm{CP}}=14.2 \mathrm{~Hz}\right.$, $\left.J_{\mathrm{CF}}=22.1 \mathrm{~Hz}\right), 125.9\left(\mathrm{dt}, J_{\mathrm{CP}}=1.9 \mathrm{~Hz}, J_{\mathrm{CF}}=6.3 \mathrm{~Hz}\right), 117.7\left(\mathrm{dt}, J_{\mathrm{CP}}=223.3 \mathrm{~Hz}, J_{\mathrm{CF}}=263.3 \mathrm{~Hz}\right)$, $116.1,62.7\left(\mathrm{~d}, J_{\mathrm{CP}}=6.4 \mathrm{~Hz}\right), 21.2,19.7\left(\mathrm{~d}, J_{\mathrm{CP}}=5.7 \mathrm{~Hz}\right) .{ }^{19} \mathrm{~F}-\mathrm{NMR}\left(\mathrm{CDCl}_{3}\right) \delta-44.9\left(\mathrm{~d}, J_{\mathrm{PF}}=\right.$ $124.9 \mathrm{~Hz}) .{ }^{31} \mathrm{P}-\mathrm{NMR}\left(\mathrm{CDCl}_{3}\right) \delta 7.53\left(\mathrm{t}, J_{\mathrm{PF}}=124.9 \mathrm{~Hz}\right)$. IR (film) 2256, 1281, 1264, 1054, 1007 , $820 \mathrm{~cm}^{-1}$. EI-MS m/z $328\left(\mathrm{M}^{+}\right)$. HR-MS (EI) calcd for $\mathrm{C}_{14} \mathrm{H}_{15} \mathrm{~N}_{2} \mathrm{O}_{3} \mathrm{~F}_{2} \mathrm{P}: 328.0788$. Found: 328.0789 .

Bis-(2-cyanoethyl) [1,1' -biphenyl]-3-yl-(difluoro)methylphosphonate (7b). Prepared from $1 \mathrm{~b}$ (5.48 g, $19.3 \mathrm{mmol})$. Purification by column chromatography on silica gel (hexane:EtOAc=1:1) gave $7 \mathbf{b}(4.82 \mathrm{~g}, 71 \%)$ as an oil. ${ }^{1} \mathrm{H} \mathrm{NMR}\left(\mathrm{CDCl}_{3}\right) \delta 7.85(1 \mathrm{H}, \mathrm{s}), 7.77(1 \mathrm{H}, \mathrm{d}, J=7.6 \mathrm{~Hz}), 7.65-$ $7.61(3 \mathrm{H}, \mathrm{m}), 7.58(1 \mathrm{H}, \mathrm{t}, J=7.6 \mathrm{~Hz}), 7.47(2 \mathrm{H}, \mathrm{t}, J=7.4 \mathrm{~Hz}), 7.39(1 \mathrm{H}, \mathrm{t}, J=7.4 \mathrm{~Hz}), 4.49-$ $4.39(2 \mathrm{H}, \mathrm{m}), 4.34-4.24(2 \mathrm{H}, \mathrm{m}), 2.83-2.78(4 \mathrm{H}, \mathrm{m}) .{ }^{13} \mathrm{C} \mathrm{NMR}\left(\mathrm{CDCl}_{3}\right) \delta 141.6,139.3,131.6$ $\left(\mathrm{dt}, J_{\mathrm{CP}}=14.1 \mathrm{~Hz}, J_{\mathrm{CF}}=21.7 \mathrm{~Hz}\right), 129.8,129.1,128.7,127.8,126.9,124.7\left(\mathrm{t}, J_{\mathrm{CF}}=5.4 \mathrm{~Hz}\right)$, $124.4\left(\mathrm{t}, J_{\mathrm{CF}}=6.0 \mathrm{~Hz}\right), 117.5\left(\mathrm{dt}, J_{\mathrm{CP}}=222.0 \mathrm{~Hz}, J_{\mathrm{CF}}=263.7 \mathrm{~Hz}\right), 116.1,62.7\left(\mathrm{~d}, J_{\mathrm{CP}}=6.4 \mathrm{~Hz}\right)$, $19.5\left(\mathrm{~d}, J_{\mathrm{CP}}=5.6 \mathrm{~Hz}\right) .{ }^{19} \mathrm{~F}-\mathrm{NMR}\left(\mathrm{CDCl}_{3}\right) \delta-45.2\left(\mathrm{~d}, J_{\mathrm{PF}}=122.4 \mathrm{~Hz}\right) .{ }^{31} \mathrm{P} \mathrm{NMR}\left(\mathrm{CDCl}_{3}\right) \delta 7.33$ $\left(\mathrm{t}, J_{\mathrm{PF}}=122.4 \mathrm{~Hz}\right)$. IR (film) 2256, 1281, 1226, 1048, 1006, $760 \mathrm{~cm}^{-1}$. EI-MS m/z $390\left(\mathrm{M}^{+}\right)$. Anal. Calcd for $\mathrm{C}_{19} \mathrm{H}_{17} \mathrm{~N}_{2} \mathrm{O}_{3} \mathrm{~F}_{2} \mathrm{P}: \mathrm{C}, 58.47 ; \mathrm{H}, 4.39 ; \mathrm{N}, 7.18$. Found: C, 58.75; H, 4.41; N, 7.01.

Bis-(2-cyanoethyl) difluoro(1-naphthyl)methylphosphonate (7c). Prepared from 1c $(5.31 \mathrm{~g}$, $20.6 \mathrm{mmol}$ ). Purification by column chromatography on silica gel (hexane:EtOAc=1:1) gave 7c $(6.4 \mathrm{~g}, 85 \%)$ as an oil. ${ }^{1} \mathrm{H} \mathrm{NMR}\left(\mathrm{CDCl}_{3}\right) \delta 8.38(1 \mathrm{H}, \mathrm{d}, J=8.7 \mathrm{~Hz}), 8.02(1 \mathrm{H}, \mathrm{d}, J=8.3 \mathrm{~Hz})$, $7.91(1 \mathrm{H}, \mathrm{d}, J=8.1 \mathrm{~Hz}), 7.85(1 \mathrm{H}, \mathrm{d}, J=7.4 \mathrm{~Hz}), 7.63-7.46(3 \mathrm{H}, \mathrm{m}), 4.47-4.32(2 \mathrm{H}, \mathrm{m}), 4.28-$ 
$4.15(2 \mathrm{H}, \mathrm{m}), 2.78-2.58(4 \mathrm{H}, \mathrm{m}) .{ }^{13} \mathrm{C} \mathrm{NMR}\left(\mathrm{CDCl}_{3}\right) \delta 133.7,132.4,129.2,128.6,127.0,126.6$ $\left(\mathrm{t}, J_{\mathrm{CP}}=13.9 \mathrm{~Hz}, J_{\mathrm{CF}}=19.9 \mathrm{~Hz}\right), 126.3\left(\mathrm{dt}, J_{\mathrm{CP}}=3.6 \mathrm{~Hz}, J_{\mathrm{CF}}=9.8 \mathrm{~Hz}\right), 126.2,125.0\left(\mathrm{t}, J_{\mathrm{CF}}=4.7\right.$ $\mathrm{Hz}), 124.3,119.2\left(\mathrm{dt}, J_{\mathrm{CP}}=220.7 \mathrm{~Hz}, J_{\mathrm{CF}}=264.6 \mathrm{~Hz}\right), 116.1,62.6\left(\mathrm{~d}, J_{\mathrm{CP}}=6.5 \mathrm{~Hz}\right), 19.4\left(\mathrm{~d}, J_{\mathrm{CP}}\right.$ $=5.9 \mathrm{~Hz}) .{ }^{19} \mathrm{~F}-\mathrm{NMR}\left(\mathrm{CDCl}_{3}\right) \delta-39.0\left(\mathrm{~d}, J_{\mathrm{PF}}=120.9 \mathrm{~Hz}\right) .{ }^{31} \mathrm{P} \mathrm{NMR}\left(\mathrm{CDCl}_{3}\right) \delta 7.50\left(\mathrm{t}, J_{\mathrm{PF}}=\right.$ $120.9 \mathrm{~Hz}$ ). IR (film) 2256, 1282, 1127, 1081, 1039, 1005, $776 \mathrm{~cm}^{-1}$. EI-MS m/z $364\left(\mathrm{M}^{+}\right)$. Anal. Calcd for $\mathrm{C}_{17} \mathrm{H}_{15} \mathrm{~N}_{2} \mathrm{O}_{3} \mathrm{~F}_{2} \mathrm{P}: \mathrm{C}, 56.05 ; \mathrm{H}, 4.15 ; \mathrm{N}, 7.69$. Found: C, 55.77; H, 4.25; N, 7.81 .

Bis-(2-cyanoethyl)difluoro(2-naphthyl)methylphosphonate (7d). Prepared from $\mathbf{1 d}^{12}$ (6.23 g, $24.1 \mathrm{mmol}$ ). Purification by column chromatography on silica gel (hexane:EtOAc=1:1) gave 7d $(5.8 \mathrm{~g}, 72 \%)$ as colorless crystals $\left(\mathrm{mp} 82-84{ }^{\circ} \mathrm{C}\right) .{ }^{1} \mathrm{H} \mathrm{NMR}\left(\mathrm{CDCl}_{3}\right) \delta 8.18(1 \mathrm{H}, \mathrm{s}), 8.02-7.94$ $(2 \mathrm{H}, \mathrm{m}), 7.90(1 \mathrm{H}, \mathrm{d}, J=8.8 \mathrm{~Hz}), 7.68(1 \mathrm{H}, \mathrm{d}, J=8.8 \mathrm{~Hz}), 7.65-7.55(2 \mathrm{H}, \mathrm{m}), 4.50-4.22(4 \mathrm{H}$, m), 2.82-2.65 (4H, m). ${ }^{13} \mathrm{C}-\mathrm{NMR}\left(\mathrm{CDCl}_{3}\right) \delta 134.2,132.2,128.8,128.3\left(\mathrm{dt}, J_{\mathrm{CP}}=14.0 \mathrm{~Hz}, J_{\mathrm{CF}}=\right.$ $21.7 \mathrm{~Hz}), 127.9,127.7,127.0,126.7\left(\mathrm{dt}, J_{\mathrm{CP}}=3.3 \mathrm{~Hz}, J_{\mathrm{CF}}=7.3 \mathrm{~Hz}\right), 122.1\left(\mathrm{t}, J_{\mathrm{CF}}=5.4 \mathrm{~Hz}\right)$, $117.8\left(\mathrm{dt}, J_{\mathrm{CP}}=222.8 \mathrm{~Hz}, J_{\mathrm{CF}}=263.7 \mathrm{~Hz}\right), 116.1,62.8\left(\mathrm{~d}, J_{\mathrm{CP}}=6.5 \mathrm{~Hz}\right), 19.7\left(\mathrm{~d}, J_{\mathrm{CP}}=5.7 \mathrm{~Hz}\right)$. ${ }^{19} \mathrm{~F}-\mathrm{NMR}\left(376 \mathrm{MHz}, \mathrm{CDCl}_{3}\right) \delta-44.9\left(\mathrm{~d}, J_{\mathrm{PF}}=123.5 \mathrm{~Hz}\right) .{ }^{31} \mathrm{P} \mathrm{NMR}\left(\mathrm{CDCl}_{3}\right) \delta 7.45\left(\mathrm{t}, J_{\mathrm{PF}}=\right.$ $123.5 \mathrm{~Hz})$. IR (KBr) 2253, 1278, 1133, 1049, $745 \mathrm{~cm}^{-1}$. EI-MS m/z $364\left(\mathrm{M}^{+}\right)$. Anal. Calcd for $\mathrm{C}_{17} \mathrm{H}_{15} \mathrm{~N}_{2} \mathrm{O}_{3} \mathrm{~F}_{2} \mathrm{P}: \mathrm{C}, 56.05 ; \mathrm{H}, 4.15 ; \mathrm{N}, 7.69$. Found: C, 55.75; H, 4.28; N, 7.66.

Bis-(2-cyanoethyl) \{3-[bis-(methylsulfonyl)amino]-4-[(E)-2-phenylethenyl]phenyl\} (difluoro)-methylphosphonate (7e). Prepared from 1e (4.53 g, 9.4 mmol). Column chromatography on silica gel (hexane:EtOAc $=1: 1)$ gave 7 e $(3.91 \mathrm{~g}, 71 \%)$ as colorless crystals $\left(\mathrm{mp} 150-151{ }^{\circ} \mathrm{C}\right) .{ }^{1} \mathrm{H}-\mathrm{NMR}\left(\mathrm{CD}_{3} \mathrm{COCD}_{3}\right) \delta 8.14(1 \mathrm{H}, \mathrm{d}, J=8.3 \mathrm{~Hz}), 7.81(1 \mathrm{H}, \mathrm{d}, J=8.3 \mathrm{~Hz})$, $7.77(1 \mathrm{H}, \mathrm{s}), 7.65(2 \mathrm{H}, \mathrm{d}, J=7.5 \mathrm{~Hz}), 7.55(1 \mathrm{H}, \mathrm{d}, J=16.5 \mathrm{~Hz}), 7.48(1 \mathrm{H}, \mathrm{d}, J=16.5 \mathrm{~Hz}), 7.43$ $(2 \mathrm{H}, \mathrm{t}, J=8.3 \mathrm{~Hz}), 7.35(1 \mathrm{H}, \mathrm{t}, J=8.3 \mathrm{~Hz}), 4.55-4.34(4 \mathrm{H}, \mathrm{m}), 3.56(6 \mathrm{H}, \mathrm{s}), 2.99-2.89(4 \mathrm{H}, \mathrm{m})$. $\left.{ }^{13} \mathrm{C}-\mathrm{NMR} \mathrm{CD} \mathrm{COCD}_{3}\right) \delta 142.8,137.4,135.7,133.5,132.7\left(\mathrm{dt}, J_{\mathrm{CP}}=14.0 \mathrm{~Hz}, J_{\mathrm{CF}}=22.7 \mathrm{~Hz}\right)$, $130.8\left(\mathrm{t}, J_{\mathrm{CF}}=5.7 \mathrm{~Hz}\right), 129.9,129.8,129.2\left(\mathrm{t}, J_{\mathrm{CF}}=5.6 \mathrm{~Hz}\right), 128.2,127.9,123.3,118.1\left(\mathrm{dt}, J_{\mathrm{CP}}=\right.$ $\left.221.6 \mathrm{~Hz}, J_{\mathrm{CF}}=263.8 \mathrm{~Hz}\right), 117.7,64.6\left(\mathrm{~d}, J_{\mathrm{CP}}=6.5 \mathrm{~Hz}\right), 43.8,20.2\left(\mathrm{~d}, J_{\mathrm{CP}}=6.0 \mathrm{~Hz}\right) .{ }^{19} \mathrm{~F} \mathrm{NMR}$ $\left(\mathrm{CD}_{3} \mathrm{COCD}_{3}\right) \delta-45.9\left(\mathrm{~d}, J_{\mathrm{PF}}=117.5 \mathrm{~Hz}\right) .{ }^{31} \mathrm{P} \mathrm{NMR}\left(\mathrm{CD}_{3} \mathrm{COCD}_{3}\right) \delta 3.81\left(\mathrm{t}, J_{\mathrm{PF}}=117.5 \mathrm{~Hz}\right) . \mathrm{IR}$ (KBr) 3012, 2974, 2953, 2253, 1607, 1365, 1164, $1038 \mathrm{~cm}^{-1}$. ESI-MS m/z $610\left(\mathrm{MNa}^{+}\right), 588$ $\left(\mathrm{MH}^{+}\right)$. HR-MS (ESI) calcd for $\mathrm{C}_{23} \mathrm{H}_{25} \mathrm{~N}_{3} \mathrm{O}_{7} \mathrm{~F}_{2} \mathrm{PS}_{2}\left(\mathrm{MH}^{+}\right)$: 588.0840. Found: 588.0853. Anal. Calcd for $\mathrm{C}_{23} \mathrm{H}_{24} \mathrm{~N}_{3} \mathrm{O}_{7} \mathrm{~F}_{2} \mathrm{PS}_{2} .3 / 2 \mathrm{H}_{2} \mathrm{O}$ : C, 44.95; H, 4.43; N, 6.84. Found: C, 45.02; H, 4.46; N, 6.88 .

Typical example of thionylation of bis-(2-cyanoethyl) phosphonates with Lawesson's reagent. $O, O$-Bis-(2-cyanoethyl) difluoro(4-methylphenyl)methylphosphonothioate (8a). A solution of 7a $(2.41 \mathrm{~g}, 7.34 \mathrm{mmol})$ and Lawesson's reagent $(1.78 \mathrm{~g}, 4.4 \mathrm{mmol})$ in toluene $(7 \mathrm{~mL})$ was heated at $100{ }^{\circ} \mathrm{C}$ for $30 \mathrm{~min}$. After cooling to RT, the resulting precipitates were filtered off. The filtrates were evaporated and the residue was chromatographed on silica gel (hexane:EtOAc $=4: 1)$ to give $8 \mathrm{a}(1.3 \mathrm{~g}, 52 \%)$ as an oil. ${ }^{1} \mathrm{H} \mathrm{NMR}\left(\mathrm{CDCl}_{3}\right) \delta 7.48(2 \mathrm{H}, \mathrm{d}, J=6.9$ $\mathrm{Hz}), 7.27(2 \mathrm{H}, \mathrm{d}, J=6.9 \mathrm{~Hz}), 4.44-4.32(2 \mathrm{H}, \mathrm{m}), 4.31-4.16(2 \mathrm{H}, \mathrm{m}), 2.82-2.60$ (4H, m), 2.39 $(3 \mathrm{H}, \mathrm{s}) .{ }^{13} \mathrm{C} \mathrm{NMR}\left(\mathrm{CDCl}_{3}\right) \delta 141.5,129.0,127.9\left(\mathrm{dt}, J_{\mathrm{CP}}=15.3 \mathrm{~Hz}, J_{\mathrm{CF}}=22.5 \mathrm{~Hz}\right), 126.6\left(\mathrm{t}, J_{\mathrm{CF}}\right.$ $=3.1 \mathrm{~Hz}), 119.0\left(\mathrm{dt}, J_{\mathrm{CP}}=185.3 \mathrm{~Hz}, J_{\mathrm{CF}}=268.5 \mathrm{~Hz}\right), 116.1,62.5\left(\mathrm{~d}, J_{\mathrm{CP}}=6.0 \mathrm{~Hz}\right), 21.3,19.6(\mathrm{~d}$, 
$\left.J_{\mathrm{CP}}=6.6 \mathrm{~Hz}\right) .{ }^{19} \mathrm{~F} \mathrm{NMR}\left(\mathrm{CDCl}_{3}\right) \delta-44.5\left(\mathrm{~d}, J_{\mathrm{PF}}=130.9 \mathrm{~Hz}\right) ;{ }^{31} \mathrm{P} \mathrm{NMR}\left(\mathrm{CDCl}_{3}\right) \delta 78.3\left(\mathrm{t}, J_{\mathrm{PF}}=\right.$ $130.9 \mathrm{~Hz}$ ). IR (film) 2254, 1263, 1101, 1028, 1004, $801 \mathrm{~cm}^{-1}$. EI-MS m/z $344\left(\mathrm{M}^{+}\right)$. HR-MS (EI) calcd for $\mathrm{C}_{14} \mathrm{H}_{15} \mathrm{~N}_{2} \mathrm{O}_{2} \mathrm{~F}_{2} \mathrm{PS}: 344.0560$. Found: 344.0553 .

O,O-Bis-(2-cyanoethyl) [1,1'-biphenyl]-3-yl(difluoro)methylphosphonothioate (8b). Prepared from 7b (4.62 g, $11.8 \mathrm{mmol})$. Purification by column chromatography on silica gel (hexane:EtOAc=6:1) gave 8b $(2.3 \mathrm{~g}, 47 \%)$ as an oil. ${ }^{1} \mathrm{H} \mathrm{NMR}\left(\mathrm{CDCl}_{3}\right) \delta 7.94(1 \mathrm{H}, \mathrm{s}), 7.85(1 \mathrm{H}$, d, $J=8.9 \mathrm{~Hz}), 7.73-7.57(4 \mathrm{H}, \mathrm{m}), 7.52(2 \mathrm{H}, \mathrm{t}, J=9.0 \mathrm{~Hz}), 7.42(1 \mathrm{H}, \mathrm{t}, J=9.0 \mathrm{~Hz}), 3.93-3.76$ $(2 \mathrm{H}, \mathrm{m}), 3.72-3.57(2 \mathrm{H}, \mathrm{m}), 1.76(4 \mathrm{H}, \mathrm{t}, J=7.5 \mathrm{~Hz}) .{ }^{13} \mathrm{C}$ NMR $\left(\mathrm{CDCl}_{3}\right) \delta 141.4,139.8,131.5$ $\left(\mathrm{dt}, J_{\mathrm{CP}}=15.1 \mathrm{~Hz}, J_{\mathrm{CF}}=22.0 \mathrm{~Hz}\right), 129.9,128.9,127.9,127.1,125.5,125.4,118.9\left(\mathrm{dt}, J_{\mathrm{CP}}=\right.$ $\left.183.5 \mathrm{~Hz}, J_{\mathrm{CF}}=268.8 \mathrm{~Hz}\right), 116.1,62.6\left(\mathrm{~d}, J_{\mathrm{CP}}=6.0 \mathrm{~Hz}\right), 19.6\left(\mathrm{~d}, J_{\mathrm{CP}}=6.5 \mathrm{~Hz}\right) .{ }^{19} \mathrm{~F}-\mathrm{NMR}$ $\left(\mathrm{CDCl}_{3}\right) \delta-44.9\left(\mathrm{~d}, J_{\mathrm{PF}}=127.5 \mathrm{~Hz}\right) .{ }^{31} \mathrm{P}-\mathrm{NMR}\left(\mathrm{CDCl}_{3}\right) \delta 78.2\left(\mathrm{t}, J_{\mathrm{PF}}=127.5 \mathrm{~Hz}\right)$. IR (film) 2255 , 1226, 1101, 1048, 1003, 802, 758, $702 \mathrm{~cm}^{-1}$. ESI-MS m/z $407\left(\mathrm{MH}^{+}\right)$. HR-MS (ESI) calcd for $\mathrm{C}_{19} \mathrm{H}_{18} \mathrm{~N}_{2} \mathrm{O}_{2} \mathrm{~F}_{2} \mathrm{PS}\left(\mathrm{MH}^{+}\right):$407.0795. Found: 407.0803.

O,O-Bis-(2-cyanoethyl) difluoro(1-naphthyl)methylphosphonothioate (8c). Prepared from 7c $(2.2 \mathrm{~g}, 6.0 \mathrm{mmol})$. Purification by column chromatography on silica gel (hexane:EtOAc=3:1) gave $8 \mathrm{c}(1.0 \mathrm{~g}, 49 \%)$ as an oil. ${ }^{1} \mathrm{H}$ NMR $\left(\mathrm{CDCl}_{3}\right) \delta 8.38(1 \mathrm{H}, \mathrm{d}, J=8.6 \mathrm{~Hz}), 8.00(1 \mathrm{H}, \mathrm{d}, J=8.2$ $\mathrm{Hz}), 7.90(1 \mathrm{H}, \mathrm{d}, J=7.2 \mathrm{~Hz}), 7.81(1 \mathrm{H}, \mathrm{d}, J=7.2 \mathrm{~Hz}), 7.64-7.52(3 \mathrm{H}, \mathrm{m}), 4.44-4.28(2 \mathrm{H}, \mathrm{m})$, 4.22-4.12 (2H, m), $2.63(4 \mathrm{H}, \mathrm{t}, J=6.3 \mathrm{~Hz}) .{ }^{13} \mathrm{C}$ NMR $\left(\mathrm{CDCl}_{3}\right) \delta 133.7,132.3,129.5,128.7$, $127.7\left(\mathrm{dt}, J_{\mathrm{CP}}=3.3 \mathrm{~Hz}, J_{\mathrm{CF}}=9.7 \mathrm{~Hz}\right), 126.8,126.4\left(\mathrm{dt}, J_{\mathrm{CP}}=14.7 \mathrm{~Hz}, J_{\mathrm{CF}}=19.9 \mathrm{~Hz}\right), 126.0$, $125.4\left(\mathrm{t}, J_{\mathrm{CF}}=6.0 \mathrm{~Hz}\right), 124.3,120.6\left(\mathrm{dt}, J_{\mathrm{CP}}=183.0 \mathrm{~Hz}, J_{\mathrm{CF}}=270.1 \mathrm{~Hz}\right), 116.1,62.4\left(\mathrm{~d}, J_{\mathrm{CP}}=\right.$ $6.0 \mathrm{~Hz}), 19.3\left(\mathrm{~d}, J_{\mathrm{CP}}=6.6 \mathrm{~Hz}\right) \cdot{ }^{19} \mathrm{~F}-\mathrm{NMR}\left(\mathrm{CDCl}_{3}\right) \delta-37.5\left(\mathrm{~d}, J_{\mathrm{PF}}=128.1 \mathrm{~Hz}\right) .{ }^{31} \mathrm{P}-\mathrm{NMR}$ $\left(\mathrm{CDCl}_{3}\right) \delta 78.3\left(\mathrm{t}, J_{\mathrm{PF}}=128.1 \mathrm{~Hz}\right.$ ). IR (film) 1594, 1261, 1115, $1027 \mathrm{~cm}^{-1}$. EI-MS m/z $380\left(\mathrm{M}^{+}\right)$. HR-MS (EI) calcd for $\mathrm{C}_{17} \mathrm{H}_{15} \mathrm{~N}_{2} \mathrm{O}_{2} \mathrm{~F}_{2} \mathrm{PS}: 380.0560$. Found: 380.0566 .

O,O-Bis-(2-cyanoethyl) difluoro(2-naphthyl)methylphosphonothioate (8d). Prepared from 7d $(1.67 \mathrm{~g}, 4.58 \mathrm{mmol})$. Purification by column chromatography on silica gel (hexane:EtOAc=5:1) gave 8d $(1.59 \mathrm{~g}, 91 \%)$ as colorless crystal $\left(\mathrm{mp} 54-55^{\circ} \mathrm{C}\right) .{ }^{1} \mathrm{H}-\mathrm{NMR}\left(\mathrm{CDCl}_{3}\right) \delta 8.15(1 \mathrm{H}, \mathrm{s})$, 8.00-7.86 (3H, m), $7.66(1 \mathrm{H}, \mathrm{d}, J=8.6 \mathrm{~Hz}), 7.63-7.55(2 \mathrm{H}, \mathrm{m}), 4.45-4.33(2 \mathrm{H}, \mathrm{m}), 4.31-4.19$ $(2 \mathrm{H}, \mathrm{m}), 2.70(4 \mathrm{H}, \mathrm{t}, J=6.1 \mathrm{~Hz}) .{ }^{13} \mathrm{C} \mathrm{NMR}\left(\mathrm{CDCl}_{3}\right) \delta 134.2,132.1,128.8,128.3,128.2\left(\mathrm{dt}, J_{\mathrm{CP}}\right.$ $\left.=18.6 \mathrm{~Hz}, J_{\mathrm{CF}}=25.6 \mathrm{~Hz}\right), 127.8,127.7,127.3\left(\mathrm{dt}, J_{\mathrm{CP}}=3.3 \mathrm{~Hz}, J_{\mathrm{CF}}=6.7 \mathrm{~Hz}\right), 126.9,122.9(\mathrm{t}$, $\left.J_{\mathrm{CF}}=5.6 \mathrm{~Hz}\right), 119.0\left(\mathrm{dt}, J_{\mathrm{CP}}=185.1 \mathrm{~Hz}, J_{\mathrm{CF}}=268.8 \mathrm{~Hz}\right), 116.2,62.6\left(\mathrm{~d}, J_{\mathrm{CP}}=6.0 \mathrm{~Hz}\right), 19.6(\mathrm{~d}$, $\left.J_{\mathrm{CP}}=6.5 \mathrm{~Hz}\right) .{ }^{19} \mathrm{~F} \mathrm{NMR}\left(\mathrm{CDCl}_{3}\right) \delta-44.4\left(\mathrm{~d}, J_{\mathrm{PF}}=129.6 \mathrm{~Hz}\right) .{ }^{31} \mathrm{P}-\mathrm{NMR}\left(\mathrm{CDCl}_{3}\right) \delta 78.0\left(\mathrm{t}, J_{\mathrm{PF}}=\right.$ $129.6 \mathrm{~Hz}$ ). IR (film) 2254, 1419, 1262, 1071, 1029, 1002, $795 \mathrm{~cm}^{-1}$. EI-MS m/z $380\left(\mathrm{M}^{+}\right)$. Anal. Calcd for $\mathrm{C}_{17} \mathrm{H}_{15} \mathrm{~N}_{2} \mathrm{O}_{2} \mathrm{~F}_{2} \mathrm{PS} .1 / 2 \mathrm{H}_{2} \mathrm{O}$ : C, 52.44; H, 4.14; N, 7.19. Found: C, 52.08; H, 4.08; N, 6.96.

O,O-Bis-(2-cyanoethyl) \{3-[bis-(methylsulfonyl)amino]-4-[(E)-2-phenylethenyl]phenyl\}(difluoro)-methylphosphonothioate (8e). Prepared from 7e (2.92 g, $4.97 \mathrm{mmol})$. Purification by column chromatography on silica gel (hexane:EtOAc=1:1) gave $8 \mathbf{e}(2.22 \mathrm{~g}, 74 \%)$ as crystals (mp $\left.148-149^{\circ} \mathrm{C}\right) .{ }^{1} \mathrm{H}$ NMR $\left(\mathrm{CDCl}_{3}\right) \delta 7.90(1 \mathrm{H}, \mathrm{d}, J=8.3 \mathrm{~Hz}), 7.75(1 \mathrm{H}, \mathrm{d}, J=8.3 \mathrm{~Hz}), 7.56$ $(1 \mathrm{H}, \mathrm{s}), 7.55(2 \mathrm{H}, \mathrm{d}, J=7.3 \mathrm{~Hz}), 7.46(1 \mathrm{H}, \mathrm{d}, J=16.2 \mathrm{~Hz}), 7.41(2 \mathrm{H}, \mathrm{t}, J=7.3 \mathrm{~Hz}), 7.34(1 \mathrm{H}, \mathrm{t}$, 
$J=7.3 \mathrm{~Hz}), 7.22(1 \mathrm{H}, \mathrm{d}, J=16.2 \mathrm{~Hz}), 4.46-4.33(2 \mathrm{H}, \mathrm{m}), 4.32-4.20$ (2H, m), 3.45 (6H, s), $2.78-$ $2.66(4 \mathrm{H}, \mathrm{m}) .{ }^{13} \mathrm{C} \mathrm{NMR}\left(\mathrm{CDCl}_{3}\right) \delta 141.7,135.8,135.3,131.7,131.2\left(\mathrm{dt}, J_{\mathrm{CP}}=15.1 \mathrm{~Hz}, J_{\mathrm{CF}}=\right.$ $23.1 \mathrm{~Hz}), 129.9,129.2,129.1,129.0,127.2,127.0,122.2,117.9\left(\mathrm{dt}, J_{\mathrm{CP}}=185.8 \mathrm{~Hz}, J_{\mathrm{CF}}=269.6\right.$ $\mathrm{Hz}), 116.3,62.9\left(\mathrm{~d}, J_{\mathrm{CP}}=5.9 \mathrm{~Hz}\right), 43.4,19.6\left(\mathrm{~d}, J_{\mathrm{CP}}=6.9 \mathrm{~Hz}\right) .{ }^{19} \mathrm{~F} \mathrm{NMR}\left(\mathrm{CDCl}_{3}\right) \delta-45.9\left(\mathrm{~d}, J_{\mathrm{PF}}\right.$ $=126.6 \mathrm{~Hz}) .{ }^{31} \mathrm{P}-\mathrm{NMR}\left(\mathrm{CDCl}_{3}\right) \delta 76.7\left(\mathrm{t}, J_{\mathrm{PF}}=126.6 \mathrm{~Hz}\right) . \mathrm{IR}(\mathrm{KBr}) 3020,2937,2256,1605$, 1363, 1167, $1029 \mathrm{~cm}^{-1}$. ESI-MS m/z $604\left(\mathrm{MH}^{+}\right)$. HR-MS (ESI) calcd for $\mathrm{C}_{23} \mathrm{H}_{25} \mathrm{~N}_{3} \mathrm{O}_{6} \mathrm{~F}_{2} \mathrm{PS}_{3}$ $\left(\mathrm{MH}^{+}\right)$: 604.0611. Found: 604.0615.

\section{Typical deprotection procedure for the bis-(2-cyanoethyl) phosphonothioates}

Potassium difluoro(4-methylphenyl)methylphosphonothioate (9a). To a stirred solution of 8a $(1.15 \mathrm{~g}, 3.34 \mathrm{mmol})$ in $\mathrm{MeOH}(15 \mathrm{~mL})$ was added $\mathrm{K}_{2} \mathrm{CO}_{3}(1.38 \mathrm{~g}, 10.1 \mathrm{mmol})$. After being stirred at RT for $2.5 \mathrm{~h}$, the mixture was diluted with water and extracted with ether $(3 \times 10 \mathrm{~mL})$. The volatile component of the aqueous extracts was removed in vacuo and the resulting precipitates were purified by reversed-phase column chromatography on ODS. Elution with water gave 9a (798 $\mathrm{mg}, 76 \%)$ as colorless crystals $\left(\mathrm{mp}>250{ }^{\circ} \mathrm{C}\right)$. The spectroscopic data of 9 a were identical to those of the authentic sample prepared previously. ${ }^{9}$

Potassium [1,1'-biphenyl]-3-yl(difluoro)methylphosphonothioate (9b). Prepared from $8 b$ (2.06 g, $5.07 \mathrm{mmol}$ ). Purification by column chromatography on ODS (water) gave 9b (1.38 g, $72 \%)$ as colorless crystals $\left(\mathrm{mp}>250^{\circ} \mathrm{C}\right)$. The spectroscopic data of $\mathbf{9 b}$ were identical to those of the authentic sample prepared previously. ${ }^{9}$

Potassium difluoro(1-naphthyl)methylphosphonothioate (9c). Prepared from 8c (910 mg, $2.39 \mathrm{mmol})$. Purification by column chromatography on ODS (water) gave 9c (400 mg, 47\%) as colorless crystals $\left(\mathrm{mp}>250{ }^{\circ} \mathrm{C}\right)$. The spectroscopic data of 9c were identical to those of the authentic sample prepared previously. ${ }^{9}$

Potassium difluoro(2-naphthyl)methylphosphonothioate (9d). Prepared from 8d (1.22 g, $3.21 \mathrm{mmol}$ ). Purification by column chromatography on ODS (water) gave 9d (843 $\mathrm{mg}, 75 \%$ ) as colorless crystals $\left(\mathrm{mp}>250{ }^{\circ} \mathrm{C}\right)$. The spectroscopic data of 9d were identical to those of the authentic sample prepared previously. ${ }^{9}$

Potassium \{3-[bis-(methylsulfonyl)amino]-4[(E)-2-phenylethenyl]phenyl\}(difluoro)methyl phos-phonothioate (9e). Prepared from 8e (1.24 g, $2.05 \mathrm{mmol})$. Purification by column chromatography on ODS (water) gave 9e $(563 \mathrm{mg}, 48 \%)$ as colorless crystals (decomp. 197$\left.198^{\circ} \mathrm{C}\right) .{ }^{1} \mathrm{H}$ NMR $\left(\mathrm{D}_{2} \mathrm{O}\right) \delta 7.81(1 \mathrm{H}, \mathrm{d}, J=8.2 \mathrm{~Hz}), 7.70(1 \mathrm{H}, \mathrm{d}, J=8.2 \mathrm{~Hz}), 7.65(1 \mathrm{H}, \mathrm{s}), 7.48$ $(2 \mathrm{H}, \mathrm{d}, J=6.9 \mathrm{~Hz}), 7.29(2 \mathrm{H}, \mathrm{t}, J=6.9 \mathrm{~Hz}), 7.26-7.17(3 \mathrm{H}, \mathrm{m}), 3.44(6 \mathrm{H}, \mathrm{s}) .{ }^{13} \mathrm{C}-\mathrm{NMR}\left(\mathrm{D}_{2} \mathrm{O}\right) \delta$ $139.6,137.3\left(\mathrm{dt}, J_{\mathrm{CP}}=12.8 \mathrm{~Hz}, J_{\mathrm{CF}}=23.4 \mathrm{~Hz}\right), 136.5,134.4,130.4,129.4,129.3,129.2,127.2$, $126.9,122.3,121.7\left(\mathrm{dt}, J_{\mathrm{CP}}=136.8 \mathrm{~Hz}, J_{\mathrm{CF}}=273.2 \mathrm{~Hz}\right), 43.3 .{ }^{19} \mathrm{~F}$ NMR $\left(\mathrm{D}_{2} \mathrm{O}\right) \delta-42.3\left(\mathrm{~d}, J_{\mathrm{PF}}=\right.$ $94.7 \mathrm{~Hz}) .{ }^{31} \mathrm{P}-\mathrm{NMR}\left(\mathrm{D}_{2} \mathrm{O}\right) \delta 45.7\left(\mathrm{t}, J_{\mathrm{PF}}=94.7 \mathrm{~Hz}\right) . \mathrm{IR}(\mathrm{KBr}) 3388,1633,1366,1161,1009,763$, $523 \mathrm{~cm}^{-1}$. ESI-MS m/z $574\left(\mathrm{MH}^{+}\right)$. HR-MS (ESI) calcd for $\mathrm{C}_{17} \mathrm{H}_{17} \mathrm{NO}_{6} \mathrm{~F}_{2} \mathrm{~K}_{2} \mathrm{PS}_{3}\left(\mathrm{MH}^{+}\right)$: 573.9198. Found: 573.9211.

Difluoro(2-naphthyl)methylphosphonothioic acid (5d). The potassium salts 9d (600 mg, $1.58 \mathrm{mmol}$ ) were dissolved in water, and the solution was acidified with $1 \mathrm{M} \mathrm{HCl}$. The mixture 
was extracted with ether $(5 \times 10 \mathrm{~mL})$, and the extracts dried $\left(\mathrm{MgSO}_{4}\right)$ and concentrated. The residue was purified by column chromatography on ODS. Elution with water gave 5d (360 mg, $83 \%)$ as colorless crystals (decomp. $\left.81-83{ }^{\circ} \mathrm{C}\right) .{ }^{1} \mathrm{H}$ NMR $\left(\mathrm{D}_{2} \mathrm{O}\right) \delta 8.03(1 \mathrm{H}, \mathrm{s}), 7.82-7.69(3 \mathrm{H}$, $\mathrm{m}), 7.59(1 \mathrm{H}, \mathrm{d}, J=8.6 \mathrm{~Hz}), 7.43-7.36(2 \mathrm{H}, \mathrm{m}) .{ }^{13} \mathrm{C}-\mathrm{NMR}\left(\mathrm{D}_{2} \mathrm{O}\right) \delta 136.4,134.8,133.7\left(\mathrm{dt}, J_{\mathrm{CP}}=\right.$ $\left.13.4 \mathrm{~Hz}, J_{\mathrm{CF}}=22.3 \mathrm{~Hz}\right), 131.3,130.7,130.5,130.3,129.6,129.4\left(\mathrm{dt}, J_{\mathrm{CP}}=2.1 \mathrm{~Hz}, J_{\mathrm{CF}}=7.2 \mathrm{~Hz}\right)$, $126.2\left(\mathrm{t}, J_{\mathrm{CF}}=5.8 \mathrm{~Hz}\right), 123.6\left(\mathrm{dt}, J_{\mathrm{CP}}=157.4 \mathrm{~Hz}, J_{\mathrm{CF}}=265.8 \mathrm{~Hz}\right) .{ }^{19} \mathrm{~F} \mathrm{NMR}\left(\mathrm{D}_{2} \mathrm{O}\right) \delta-43.1(\mathrm{~d}$, $\left.J_{\mathrm{PF}}=110.5 \mathrm{~Hz}\right) .{ }^{31} \mathrm{P}-\mathrm{NMR}\left(\mathrm{D}_{2} \mathrm{O}\right) \delta 56.4\left(\mathrm{t}, J_{\mathrm{PF}}=110.5 \mathrm{~Hz}\right) . \mathrm{IR}(\mathrm{KBr}) 3637,3059,1687,1508$, $1191,948,861,814,748 \mathrm{~cm}^{-1}$. FAB-MS m/z $275\left(\mathrm{MH}^{+}\right)$. HR-MS (FAB) calcd for $\mathrm{C}_{11} \mathrm{H}_{10} \mathrm{O}_{2} \mathrm{~F}_{2} \mathrm{PS}$ $\left(\mathrm{MH}^{+}\right)$: 275.0107. Found: 275.0117.

Assay and inhibition of PTP-1B. PTP-1B activity was assessed according to the manufacturer's instructions. Briefly, the activity of PTP-1B was assessed at $25{ }^{\circ} \mathrm{C}$ in 96 -well plates with $p$ nitrophenyl phosphate ( $p$ NPP) as substrate. The assay mixture contained $5 \mu \mathrm{L}$ of $40 \mathrm{mM} \mathrm{NiCl}_{2}$ in water, $5 \mathrm{mM}$ of a bovine serum albumin solution $(5 \mathrm{mg} / \mathrm{mL}$ in water), $5 \mu \mathrm{L}$ of PTP-1B-agaroses (0.05 units) and $65 \mu \mathrm{L}$ of $50 \mathrm{mM}$ Tris- $\mathrm{HCl}$ buffer $(\mathrm{pH} 7.0) / 0.1 \mathrm{mM} \mathrm{CaCl}$ that, if indicated, contained various concentrations of inhibitor, and pre-incubation followed for $15 \mathrm{~min}$. The enzyme reaction was started by the addition of $120 \mu \mathrm{L}$ of a $p N P P$ solution $(1.5 \mathrm{mg} / \mathrm{mL}$ in $50 \mathrm{mM}$ Tris- $\mathrm{HCl}$ buffer). After incubation for $30 \mathrm{~min}$, the reaction was stopped by adding $20 \mathrm{~mL}$ of a $13 \%(\mathrm{w} / \mathrm{v}) \mathrm{K}_{2} \mathrm{HPO}_{4}$ solution, and the absorbance at $405 \mathrm{~nm}$ was measured. The non-enzymatic hydrolysis of $p$ NPP was corrected by measuring the control without the addition of enzyme. $\mathrm{IC}_{50}$ values were determined as the concentration of compounds that give $50 \%$ of the control enzyme activity. The experiments were carried out in triplicate at 5 or 8 different inhibitor concentrations. The inhibitor concentrations were plotted as the y-axis and the remaining activity (\%) as the $\mathrm{x}$-axis, and the concentration of inhibitor that give a 50\% inhibition was calculated, using the curve-fit equation, CA-Cricket Graph III.

\section{Acknowledgments}

This work was supported in part by a grant from The Promotion and Mutual Aid Corporation for Private School of Japan and the Ministry of Education, Culture, Sports, Science and Technology of Japan.

\section{References}

1. Hunter, T. Cell 2000, 100, 113.

2. (a) Blackburn, G. M. Chem. Ind. 1981, 134. (b) Blackburn, G. M.; Kent, D. E.; Kolmann, F. J. Chem. Soc., Perkin Trans. 1. 1984, 1149. (c) Burton, D. J. Yang, Z.-Y. Tetrahedron 1992, 48, 189. (d) Thatcher, G. R.; Campbell, A. S. J. Org. Chem. 1993, 58, 2272. (e) O'Hagan, D.; Rzepa, H. S. Chem. Commun. 1997, 645. (f) Taylor, S. D.; Kotoris, C. C.; Hum, G. 
Tetrahedron 1999, 55, 12431. (g) Yokomatsu, T.; Shibuya, S. J. Synth. Org. Chem. Japan (Yuki Gosei Kagaku Kyokaishi) 2002, 60, 740.

3. For the synthesis of $\alpha, \alpha$-difluoromethylenephosphonic acids with significant activity: (a) Chambers, R. D.; Jaouhari, R.; O'Hagan, D. J. Chem. Soc., Chem. Commun. 1988, 1169. (b) Martin, S. F.; Wong, Y.-L.; Wagman, A. S. J. Org. Chem. 1994, 59, 4821. (c) Halazy, S.; Ehrhard, A.; Eggenspiller, A.; Berges-Gross, V.; Danzin, C. Tetrahedron 1996, 52, 177 and references cited therein. (d) Taylor, S. D.; Kotoris, C. C.; Dinaut, A. N.; Wang, Q.; Ramachandran, C.; Hung, Z. Bioorg. Med. Chem. 1998, 6, 1457 and references cited therein. (e) Berkowitz, D. B.; Bose, M.; Pfannenstiel; Doukov, T. J. Org. Chem. 2000, 65, 4498. (f) Yokomatsu, T.; Hayakawa, Y.; Suemune, K.; Kihara, T.; Soeda, S.; Shimeno, H.; Shibuya, S. Bioorg. Med. Chem. 2000, 8, 2571. (g) Yokomatsu, T.; Murano, T.; Akiyama, T.; Koizumi, J.; Shibuya, S.; Tsuji, Y.; Soeda, S.; Shimeno, S. Bioorg. Med. Chem. Lett. 2003, $13,229$.

4. Kole, K. H.; Smyth, M. S.; Russ, P. L.; Burke, T. R. Jr. Biochem. J. 1995, 311, 1025.

5. (a) Kotoris, C. C.; Chen, M.-J.; Taylor, S. D. Bioorg. Med. Chem. Lett. 1998, 8, 3275. (b) Leung, C.; Grzyb, J.; Lee, J.; Meyer, N.; Hum, G.; Jia, C.; Liu, S.; Taylor, S. D. Bioorg. Med. Chem. 2002, 10, 2309. (c) Huang, P.; Ramphal, J.; Wei, J.; Liang, C.; Jallal, B.; McMahon, G.; Tang, C. Bioorg. Med. Chem. 2003, 11, 1835.

6. Cava, G. M.; Levinson, M. I. Tetrahedron 1985, 41, 5061.

7. Piettre, S.; Raboisson, P. Tetrahedron Lett. 1996, 37, 2229. (b) Piettre, S. Tetrahedron Lett. 1996, 37, 2233. (c) Piettre, S. Tetrahedron Lett. 1996, 37, 4707.

8. Yokomatsu, T.; Murano, T.; Umesue, I.; Soeda, S.; Shimeno, H.; Shibuya, S. Bioorg. Med. Chem. Lett. 1999, 9, 529.

9. Yokomatsu, T.; Takechi, H.; Murano, T.; Shibuya, S. J. Org. Chem. 2000, 65, 5858.

10. Swierczek, K.; Peters, J. W.; Hengge, A. C. Tetrahedron 2003, 59, 595.

11. (a) Tener, G. M. J. Am. Chem. Soc. 1961, 83, 159. (b) Letsinger, R. L.; Ogilvie, K. K.; Miller, P. S. J. Am. Chem. Soc. 1969, 91, 3360. (c) Catlin, J. C.; Cramer, F. J. Org. Chem. 1973, 38, 245.

12. Yokomatsu, T.; Murano, T.; Suemune, K.; Shibuya, S. Tetrahedron 1996, 53, 815.

13. Sangster, J. Octanol-Water Partition Coefficients: Fundamentals and Physical Chemistry; John Wiley \& Sons; New York, 1997.

14. Burke, T. R. Jr.; Ye, B.; Yan, X.; Wang, S.; Jia, Z.; Chen, L.; Zhang, Z.-Y.; Barford, D. Biochemistry 1996, 35, 15989.

15. Burke, T. R. Jr.; Zhang, Z.-Y. Biopolymer (Peptide Science) 1998, 47, 225. 